\title{
circ-Grm1 promotes pulmonary artery smooth muscle cell proliferation and migration via suppression of GRM1 expression by FUS
}

\author{
SHIJING SUN ${ }^{1,2}$, QINGYU KONG ${ }^{1}$, ZHIFENG CAI $^{1}$, MINMIN WANG $^{1}$, HAIZHAO ZHAO $^{1}$ and CUIFEN ZHAO ${ }^{1}$ \\ ${ }^{1}$ Department of Pediatrics, Qilu Hospital, Cheeloo College of Medicine, Shandong University, Jinan, Shandong 250012; \\ ${ }^{2}$ Department of Pediatrics, Qilu Hospital (Qingdao), Cheeloo College of Medicine, \\ Shandong University, Qingdao, Shandong 266034, P.R. China
}

Received June 17, 2021; Accepted September 2, 2021

DOI: $10.3892 / \mathrm{ijmm} .2021 .5035$

\begin{abstract}
Pulmonary arterial hypertension is a progressive and fatal disease. Recent studies suggest that circular RNA (circRNAs/circs) can regulate various biological processes, including cell proliferation. Therefore, it is possible that circRNA may have important roles in pulmonary artery smooth muscle cell proliferation in hypoxic pulmonary hypertension (HPH). The aim of the present study was to determine the role and mechanism of circRNA-glutamate metabotropic receptor 1 (circ-Grm1; mmu_circ_0001907) in pulmonary artery smooth muscle cell (PASMC) proliferation and migration in HPH. High-throughput transcriptome sequencing was used to screen circRNAs and targeted genes involved in HPH. Cell Counting Kit-8 (CCK-8), 5-ethynyl-2-deoxyuridine and wound healing assays were employed to assess cell viability and migration. Reverse transcription-quantitative PCR and western blotting were used to detect target gene expression in different groups. Bioinformatical approaches were used to predict the interaction probabilities of circ-Grm1 and Grm1 with FUS RNA binding protein (FUS). The interactions of circ-Grm1, Grm1 and FUS were evaluated using RNA silencing and RNA immunoprecipitation assays. The results demonstrated that circ-Grm1 was upregulated in hypoxic PASMCs. Further experiments revealed that the knockdown of circ-Grm1 could suppress the proliferation and migration of hypoxic PASMCs. Transcriptome sequencing revealed that Grm1 could be the target gene of circ-Grm1. It was found that circ-Grm1 could competitively bind to FUS and consequently downregulate Grm1. Moreover, Grm1 could inhibit
\end{abstract}

Correspondence to: Dr Cuifen Zhao, Department of Pediatrics, Qilu Hospital, Cheeloo College of Medicine, Shandong University, 107 Wenhua West Road, Jinan, Shandong 250012, P.R. China E-mail: cfzhao1@163.com

Key words: circular RNA glutamate metabotropic receptor 1, pulmonary smooth muscle cells, glutamate receptor metabotropic 1 , Rap1 signalling pathway, FUS RNA binding protein the function of circ-Grm1 by promoting the proliferative and migratory abilities of hypoxic PASMCs. The results also demonstrated that circ-Grm1 influenced the biological functions of PASMCs via the Rap1/ERK pathway by regulating Grm1. Overall, the current results suggested that circ-Grm1 was associated with HPH and promoted the proliferation and migration of PASMCs via suppression of Grm1 expression through FUS.

\section{Introduction}

Pulmonary arterial hypertension (PAH) is a rare vascular disorder with an estimated prevalence of $\sim 15$ cases per million individuals $(1,2)$. The pathogenesis of PAH is extremely complex, involving multiple pathological changes, including pulmonary vascular endothelial dysfunction, pulmonary arteriolar contraction and pulmonary vascular remodelling (3). Hypoxic pulmonary hypertension (HPH) is characterized by increasing pulmonary artery blood pressure and remodelling of structural peripheral pulmonary arteries (4). Pulmonary artery smooth cell (PASMC) hyperproliferation plays a key role in pulmonary vascular remodelling in $\mathrm{HPH}$.

At present, the treatment of PAH includes endothelin receptor antagonists, phosphodiesterase type-5 inhibitors, soluble guanylate cyclase stimulators, prostacyclins and prostacyclin receptor agonists (5). There is widespread acceptance that new drugs should focus on genetically determined targets, epigenetic modifications, DNA damage, growth factors, oestrogen signalling and hypoxic stress (6). In the SERAPHIN and GRIPHON studies, whilst recent accessible treatments for PAH have advanced substantially, the disease presents high mortality rates $(7,8)$. As the proliferation of PASMCs plays a key role in the pathogenesis of $\mathrm{PAH}$, further elucidation of the molecular mechanisms via which PASMCs participate in PAH is critical for effective treatment.

Unlike other RNAs, circular RNAs (circRNAs/circs) are non-coding RNAs, which are covalently enclosed contiguous loops and are expressed at high levels in the eukaryotic transcriptome (9). Typically, circRNAs are widely expressed in eukaryotic cells and could potentially be associated with the diagnosis and treatment of 
diseases $(10,11)$. Studies have shown that circRNAs play important roles in the pathogenesis of atherosclerosis, myocardial infarction, heart failure, cardiomyopathy, pulmonary hypertension and cell aging (12). circRNAs are also involved in regulating several biological processes, including the control of angiogenesis and smooth muscle cell functions (13). Recently, studies have revealed the function of hsa_circ_0022342 and hsa_circ_0002062 in the development of chronic thromboembolic pulmonary hypertension (14,15). mmu_circ_0000790 is associated with the structural remodelling of pulmonary vessels in mice with HPH via miR-374c/FOXC1/Notch axis (16). However, only a few reports have focused on the function of circRNAs in HPH. Therefore, the present study aimed to identify novel functional circRNAs and understand their roles in a hypoxia-induced proliferation cellular model.

Studies have shown that circRNAs play crucial roles in regulating gene expression at the transcriptional level by interacting with RNA-binding proteins (17-19). Furthermore, it has been revealed that Grm1 influenced the biological functions of PASMCs via the ERK pathway (20-23). In the present study, the RNA-binding protein (RBP) FUS interacted with circ-Grm1. circ-Grm1 was selected as the representative to study the role of circRNAs in vascular remodelling of hypoxic $\mathrm{PAH}$, and the molecular mechanism of its targeted regulation of Grm1 combined with FUS was evaluated, thereby providing a new molecular target in the study of $\mathrm{HPH}$.

\section{Materials and methods}

Isolation of PASMCs. Male, 10-12-week-old C57BL/6 mice (weight, 21-25 g) were purchased from Vital River Bioscience Co., Ltd. (Beijing, China). The mice were housed in a quiet room with a $12-\mathrm{h}$ light and dark cycle, at $22 \pm 2{ }^{\circ} \mathrm{C}$ and $60 \%$ relative humidity, with free access to food and water. This study was approved by the Ethical Animal Care and Use of Laboratory Animals Committee of Qilu Hospital, Cheeloo College of Medicine, Shandong University (approval no. KYLL-2020-002).

After 14 days, the mice were sacrificed via cervical dislocation, and the aortas were collected. The criteria used to confirm death included the cessation of heartbeat for $>5$ min and no pupillary reflex to strong light. The isolation of PASMCs from mice was conducted under a stereomicroscope, following previously described methods $(24,25)$. Under aseptic conditions, the thoracic cavity of mice was opened, and the pulmonary artery trunk and left and right pulmonary arteries were removed. The pulmonary artery vessels were isolated and washed with PBS to remove excess blood. Then, the artery vessels were scraped on both the internal and external sides of the vessel wall to remove endothelial cells. The tissue was then rinsed several times with DMEM/F12 (cat. no. D6421; Sigma-Aldrich; Merck KGaA) supplemented with $1 \%$ penicillin and streptomycin. The collected tissues were cut into $1-\mathrm{mm}^{3}$ blocks, washed with D-Hank's solution and transferred into a culture platform. PASMCs were digested by adding $1 \mathrm{mg} / \mathrm{ml}$ collagenase $\left(2 \mathrm{~h}\right.$ at $37^{\circ} \mathrm{C}$; Sigma-Aldrich; Merck $\mathrm{KGaA}$ ) and collected via filtration using nylon nets with a 70-mm diameter (Sigma-Aldrich; Merck KGaA). Then, the cells were centrifuged at $1,200 \mathrm{x}$ g for $10 \mathrm{~min}$ at $4^{\circ} \mathrm{C}$, washed with PBS and resuspended in DMEM containing 10\% FBS (cat. no. 10099141; Gibco; Thermo Fisher Scientific, Inc.). After passage at a 1:3 ratio, the cells at passage 3-5 were selected for subsequent experimentation.

PASMCs were cultured at $37^{\circ} \mathrm{C}$ under $5 \% \mathrm{CO}_{2}$ in DMEM containing $10 \%$ FBS (cat. no. 11965092; Gibco; Thermo Fisher Scientific, Inc.) and $100 \mathrm{U} / \mathrm{ml}$ penicillin/streptomycin (cat. no. P1400; Beijing Solarbio Science \& Technology Co., Ltd.). 293 cells were purchased from the American Type Culture Collection and incubated in DMEM containing 10\% FBS (cat. no. 10100147; Gibco; Thermo Fisher Scientific, Inc.) and $100 \mathrm{U} / \mathrm{ml}$ penicillin/streptomycin.

Normoxia or hypoxia exposure. Before any intervention, PASMCs were cultured in a serum-free medium for $24 \mathrm{~h}$ to synchronize the cell cycles. PASMCs were also cultured under hypoxia conditions $\left(3 \% \mathrm{O}_{2}, 5 \% \mathrm{CO}_{2}, 92 \% \mathrm{~N}_{2}\right)$, and the cells were used to conduct the subsequent experiments. For normoxia exposure, cells were maintained in a humidified incubator with $5 \% \mathrm{CO}_{2}$ and $21 \% \mathrm{O}_{2}$ at $37^{\circ} \mathrm{C}$.

High-throughput transcriptome sequencing. Total RNA from PASMCs in the normoxia $(n=2)$ and hypoxia groups $(n=3)$ was isolated using TRIzol ${ }^{\circledR}$ reagent (Invitrogen; Thermo Fisher Scientific, Inc.). circRNA and mRNA expression levels were profiled using the SEQuoia RiboDepletion kit (Bio-Rad Laboratories, Inc.) at Shanghai Fulgent Genetics Co., Ltd. Then, raw data were summarized and normalized at the transcript level using R (version 3.3.2.; https:/cran.r-project. org/bin/windows/base/old/3.2.2/), and the limma package of $\mathrm{R}$ was used for pre-processing and statistical analysis. Transcripts showing absolute $\log 2$-fold of $>1$ were considered differentially expressed, and $\mathrm{P}<0.05$ indicated a statistically significant difference between experimental and control groups.

Plasmid construction and transfection. The circ-Grm1 overexpression vector (oe-circ-Grm1) was designed, and the mouse full-length circ-Grm1 was inserted into a pCD5-ciR vector by Guangzhou Geneseed Biotech Co., Ltd. The mock vector [oe-negative control (NC)] without circ-Grm1 sequence was served as a control. Small interfering (si)RNA targeting circ-Grm1 (si-circ-1 and si-circ-2) and their correspond negative controls (si-NCs) were purchased from Shanghai GenePharma Co., Ltd. si-FUS, pcDNA3.1 (p)-FUS (p-FUS), p-Grm1 and NCs (si-NC and p-NC) were purchased from Sangon Biotech Co., Ltd. The sequences were as follows: si-circ-1, 5'-GGAGGTCTGGTTCGATGAGAA-3'; si-NC1, 5'-GCGGGAAGTAGTACGTGGTAT-3'; si-circ-2, 5'-GCT GAATATCGATGATTACAA-3'; si-NC2, 5'-GCTTGAAGA CGTACAATTATA-3'; si-FUS, 5'-GACCCATCCTAACCT ACTCAT-3'; si-NC3, 5'-GCCACTTCACACTCTCCTAAA-3'.

si-circ-1 (50 nM), si-circ-2 (50 nM), si-FUS $(20 \mu \mathrm{l} / \mathrm{ml})$, p-FUS $(4 \mu \mathrm{g})$, oe-circ-Grm1 (50 nM), p-Grm1 (4 $\mu \mathrm{g})$ and NCs (si-NC, oe-NC and p-NC) were transfected in PASMCs using Lipofectamine ${ }^{\circledR} 3000$ transfection reagent (cat. no. L3000015; Invitrogen; Thermo Fisher Scientific, Inc.) at $37^{\circ} \mathrm{C}$ for $48 \mathrm{~h}$, according to the manufacturer's procedures, when cells were at a density of $1 \times 10^{6}$. After $48 \mathrm{~h}$ of hypoxia, cells were collected for subsequent analyses. 
Cell proliferation. The proliferative abilities of the PASMCs were detected using Cell Counting Kit-8 (CCK-8; cat. no. CK04; Dojindo Laboratories, Inc.), according to the manufacturer's instructions. The cells were seeded in 96-well plates $\left(2 \times 10^{3}\right.$ cells/well $)$ in $10 \mathrm{ml}$ DMEM containing $5 \% \mathrm{FBS}$. After $48 \mathrm{~h}$ of transfection, $10 \mu \mathrm{lCCK}-8$ solution was added to each well at $0,24,48,72$ and $96 \mathrm{~h}$. Then, the cells were cultured with CCK-8 solution for $4 \mathrm{~h}$ at $37^{\circ} \mathrm{C}$. The CCK- 8 reagents and stopping solution were added to each well, and then a microplate reader (Multiskan; Thermo Fisher Scientific, Inc.). was used to determine the optical density (OD) of each well at $450 \mathrm{~nm}$.

The EdU assay was carried out with the EdU labelling/detection kit (Guangzhou RiboBio Co., Ltd.) according to the manufacturer's instructions. Cells in the logarithmic growth phase were seeded into 96 -well plates with $4 \times 10^{3}$ cells per well in $10 \mathrm{ml}$ DMEM containing $10 \% \mathrm{FBS}$. Each well was incubated with $50 \mu \mathrm{M}$ EdU solution for $2 \mathrm{~h}$ and washed with PBS twice for $5 \mathrm{~min}$. Then, PBS containing $4 \%$ paraformaldehyde was used to fix cells at room temperature for $30 \mathrm{~min}$, and the cells in each well were incubated in 1X Apollo staining solution for $30 \mathrm{~min}$ at room temperature. Finally, 1X Hoechst 33342 solution was added to each well and incubated at room temperature in the dark for $30 \mathrm{~min}$ to stain DNA for observation under a fluorescence microscope (Olympus Corporation, magnification, $\mathrm{x} 100)$.

Cell migration. The migration of PASMCs was measured using a wound healing assay, wherein $2.5 \times 10^{4}$ cells $/ \mathrm{cm}^{2}$ PASMCs were seeded into six-well plates and cultured overnight in the starvation medium (DMEM containing 5\% FBS) for $24 \mathrm{~h}$. Once the cells reached $\sim 80 \%$ confluence (or more), the monolayers were scratched using a sterile $200-\mu 1$ pipette tip. Then the prepared and filled plates were washed with 3-5 ml PBS solution. Next, images at 0 and $24 \mathrm{~h}$ were obtained under a stereomicroscope (magnification, x100; Thermo Fisher Scientific, Inc.). ImageJ software v2.1.4.7 (National Institutes of Health) was used to detect the width of the scratch, and the migratory abilities of PASMCs were determined by the number of cells that crossed into the wound area from their reference point at $0 \mathrm{~h}$.

RNA extraction and reverse transcription-quantitative $(R T-q) P C R$. Total RNA was extracted from cultured cells using TRIzol reagent. RNA $(1 \mu \mathrm{g})$ was reverse transcribed to cDNA for a final volume of $20 \mu \mathrm{l}$ using the PrimeScript RT Reagent kit (Takara Biotechnology Co., Ltd.) at $16^{\circ} \mathrm{C}$ for $30 \mathrm{~min}, 42^{\circ} \mathrm{C}$ for $30 \mathrm{~min}$ and $85^{\circ} \mathrm{C}$ for $5 \mathrm{~min}$. $\mathrm{qPCR}$ analyses were performed with the SYBR ${ }^{\circledR}$ Premix Ex Taq ${ }^{\mathrm{TM}}$ kit (cat. no. RR420A; Takara Biotechnology Co., Ltd.) using the ABI PRISM ${ }^{\circledR} 7500$ Sequence Detection system (Applied Biosystems; Thermo Fisher Scientific, Inc.). The following thermocycling conditions were used for qPCR: Initial denaturation at $95^{\circ} \mathrm{C}$ for $10 \mathrm{~min}$, followed by 40 cycles at $95^{\circ} \mathrm{C}$ for $10 \mathrm{sec}, 60^{\circ} \mathrm{C}$ for $20 \mathrm{sec}$ and $72^{\circ} \mathrm{C}$ for $30 \mathrm{sec}$. Changes in the target genes were determined based on the relative values of $2^{-\Delta \Delta \mathrm{Cq}}(26)$. The primer sequences used are as follows: circ-Grm1 forward, 5'-GTCTGGAGAGGAGGTCTGGT-3' and reverse, 5'-GGCATACGTAGCCGAGGAAAA-3'; Grm1 forward, 5'-GAGCTGAGGTGTCTGCGAAC-3' and reverse,
5'-GCCATAAGCTGGACGCTGAG-3'; FUS forward, 5'-CAA TAAATTTGGTGGTCCTCGG-3' and reverse, 5'-GGCCTT GCACGAAGATGGTA-3'; GAPDH forward, 5'-GAGGGA TGCTGCCCTTACCC-3' and reverse, 5'-TTGTCTACGGGA CGAGGAAAC-3'.

Western blot analysis. Protein samples were extracted and quantified using RIPA buffer (BioVision, Inc.) and a protein concentration detection kit (Guangzhou Yingdante Science \& Technology Co., Ltd.). These proteins $(50 \mu \mathrm{g})$ were separated via 12\% SDS-PAGE (cat. no. P0690; Beyotime Institute of Biotechnology) and transferred to a PVDF membrane (cat. no. SF1J090I08; MilliporeSigma). After being blocked with $5 \%$ BSA (Thermo Fisher Scientific, Inc.) for $2 \mathrm{~h}$ at $25^{\circ} \mathrm{C}$, the membrane was incubated with the following specific primary antibodies overnight at $4^{\circ} \mathrm{C}$ : Anti-cyclin A (1:1,000; cat. no. 4656), anti-proliferating cell nuclear antigen (PCNA; 1:1,000; cat. no. 2586), anti-GAPDH (1:1,000; cat. no. 97166), anti-ERK1 (1:1,000; cat. no. 4372), anti-Rap1 (1:1,000; cat. no. 2326; all from Cell Signaling Technology, Inc.), anti-phosphorylated (ph)-ERK1 (1:1,000; cat. no. BS-1522R; Thermo Fisher Scientific, Inc.), anti-Grm1 (1:1,000; cat. no. ab183712), anti-CDK1 (1:1,000; cat. no. ab265590) and anti-Ki67 (1:1,000; cat. no. ab16667; all from Abcam). This was followed by incubation with the HRP-labeled secondary antibody at room temperature for 2 h (1:1,000; mouse secondary antibody, cat. no. ab150113; 1:1,000; rabbit secondary antibody, cat. no. ab6721; both from Abcam). Finally, the proteins were visualized using a ECL reagent (cat. no. P0020; Beyotime Institute of Biotechnology) to obtain images. The relative expression of target proteins was calculated using ImageJ software v2.1.4.7 (National Institutes of Health).

RNA immunoprecipitation (RIP) assay. The EZ-Magna RIP kit (MilliporeSigma) was used for the RIP assay, following the manufacturer's protocol. PASMCs were cross-linked by treating with formaldehyde for $10 \mathrm{~min}$ at $37^{\circ} \mathrm{C}$. After washing with cold PBS, cells were incubated in $4 \mathrm{ml}$ cell lysis buffer for $15 \mathrm{~min}$ in ice. After nuclear extraction using a Dounce homogenizer (Wheaton; DWK Life Sciences), the chromatin was sheared by sonication ( $25 \%$ power, $4.5 \mathrm{sec}$ impact, $9 \mathrm{sec}$ clearance, 14 times) at $37^{\circ} \mathrm{C}$. Then, PASMCs were incubated with RIP buffer containing magnetic beads conjugated with anti-FUS or control antibodies ( $\operatorname{IgG})$, at $4^{\circ} \mathrm{C}$ for $6 \mathrm{~h}$ by following DNase treatment for $30 \mathrm{~min}$ at room temperature. The beads were washed using the washing buffer, and the proteins were removed from the compounds via incubation with $0.1 \% \mathrm{SDS} / 0.5 \mathrm{mg} / \mathrm{ml}$ Proteinase $\mathrm{K}\left(30 \mathrm{~min}, 55^{\circ} \mathrm{C}\right)$. The RNA concentrations were detected using NanoDrop spectrophotometry (Thermo Fisher Scientific, Inc.), and the RNA qualities were analysed using a bioanalyzer (Agilent Technologies, Inc.).

Pull-down assay. The RNA pull-down assay was used to identify the circ-Grm1 interaction with FUS using a Magnetic RNA-protein pull-down kit (Thermo Fisher Scientific, Inc.). Briefly, before harvesting, PASMCs were transfected with $50 \mathrm{nM}$ biotinylated DNA probe complementary to circ-Grm1 or negative control (Genepharm, Inc.) probe for $48 \mathrm{~h}$. Then, the 
PASMCs were washed with PBS and incubated for $10 \mathrm{~min}$ in the cell lysis buffer (Thermo Fisher Scientific, Inc.) on ice. Part of the lysates were aliquoted for input. The remaining lysates were incubated with streptavidin magnetic beads (Thermo Fisher Scientific, Inc.) precoated with 5\% RNase-free BSA (Thermo Fisher Scientific, Inc.) and yeast transfer RNA (MilliporeSigma) at $4^{\circ} \mathrm{C}$ for $30 \mathrm{~min}$. After washing and elution of RNA-binding protein complexes, the proteins in the pull-down materials were analysed via western blotting using an antibody recognizing FUS (1:1,000; cat. no. ab124923; Abcam).

Actinomycin D inhibition assay. The RNA stability of Grm1 mRNA was determined using an Actinomycin D inhibition assay as described previously $(27,28)$. Firstly, the circ-Grm1 and FUS siRNAs were transfected into PASMCs, which were then treated with actinomycin D $(5 \mu \mathrm{g} / \mathrm{ml}$; Sigma-Aldrich; Merck KGaA) at $37^{\circ} \mathrm{C}$ for $0,3,6$ and $9 \mathrm{~h}$. The total RNA was isolated, and Grm1 mRNA expression was quantified via RT-qPCR, as aforementioned. RNA half-life $\left(\mathrm{t}_{1 / 2}\right)$ was calculated using linear regression analysis as described previously $(27,28)$.

Bioinformatics analyses. The relationships of circ-Grm1 and Grm1 with FUS were predicted by the bioinformatical analysis tool starBase v 2.0 (http://starbase.sysu.edu.cn/index. php) though 'RBP-target' plate. Bioinformatical (RPISeq Version 1.0; http://pridb.gdcb.iastate.edu/RPISeq/) tools were used to predict the interaction probabilities of circ-Grm1 and Grm1 with FUS. For Kyoto Encyclopedia of Genes and Genomes (KEGG, https://www.genome.jp/kegg/pathway. html) analyses, Grm1 expression was treated as a numeric variable. The Pearson correlation coefficient of other genes and Grm1 expression was calculated, and then the genes were sequenced according to the correlation coefficient. KEGG analyses based on the Grm1-related gene were conducted using the clusterProfiler R package (https://bioconductor. org/packages/release/bioc/html/clusterProfiler.html, version no. 4.0.5) (29) (organism='mmu', P-value Cutoff=0.05) to evaluate the potential biological mechanisms mediating Grm1-related HPH.

Statistical analysis. All experimental values are shown as the mean \pm SD obtained using SPSS 26.0 statistical analysis (IBM Corp.). All experiments were performed independently in triplicate. The two-tailed Student's t-test was used to compare the differences among two groups, whereas comparison among multiple groups was analysed using a one-way ANOVA with a Tukey's post hoc test. $\mathrm{P}<0.05$ was considered to indicate a statistically significant difference.

\section{Results}

circ-Grml is associated with the pathogenesis of PAH in hypoxic PASMCs. To evaluate the altered phenotype of PAH-PASMCs, cell libraries of primary cultured PASMCs from mice lung tissues were established (Fig. 1A). The results of high-throughput transcriptome sequencing demonstrated that circ-Grm1 expression increased in the hypoxic groups and showed higher expression levels compared with the control group (Fig. 1B and C). Additionally, the high-throughput transcriptome sequencing analyses showed that the expression of circ-Grm1 was elevated in the hypoxic PASMCs compared with the normxia group (Fig. 1D). These results suggested that hypoxia could promote the expression level of circ-Grm1 in PASMCs.

Silencing of circ-Grml suppresses the proliferation and migration of hypoxic PASMCs. To assess the significance of circ-Grm1 in hypoxic PASMCs, the expression of circ-Grm1 was knocked down using the RNA silencing technique. The results of RT-qPCR analysis demonstrated the efficiency of RNA silencing, which revealed successful downregulation of circ-Grm1 at the RNA level (Fig. 2A). Then, the effects of circ-Grm1 silencing on the proliferative ability of hypoxic PASMCs were detected using CCK-8 and EdU assays (Fig. 2B-D). Additionally, the expression levels of proliferation-associated proteins (cyclin A, PCNA, CDK1 and Ki67) were estimated via western blot analysis. As shown in Fig. 2D, the expression levels of these proteins were significantly downregulated after the knockdown of circ-Grm1 compared with the si-NC group. These findings suggested that the knockdown of circ-Grm1 could inhibit the proliferation of PASMCs.

As shown in Fig. 2E, the results of the wound healing assay indicated that knockdown of circ-Grm1 significantly decreased the migration of PASMCs. Furthermore, the effects of circ-Grm1 knockdown on migration were also confirmed by detecting the expression levels of migration-associated proteins, MMP-2 and MMP-9. The results demonstrated that the knockdown of circ-Grm1 significantly decreased MMP-2 and MMP-9 expression in PASMCs (Fig. 2D). Collectively, it was suggested that silencing of circ-Grm1 inhibited the proliferation and migration of hypoxic PASMCs.

Grml is targeted by circ-Grml and circ-Grml can bind with FUS. Fig. 3A and B show the volcano map and heat map analyses measured via high-throughput transcriptome sequencing, respectively. The results of high-throughput transcriptome sequencing suggested that the expression level of Grm1 was significantly lower in the hypoxic group compared with that of the normxia group (Fig. 3C) and varied inversely with the expression of circ-Grm1 (Fig. 3D) in hypoxic and normxia group. The bioinformatical analysis tool starBase v 2.0 (http://starbase.sysu.edu.cn/index.php) was used to predict whether GRM1 could bind to FUS. FUS is a multifunctional RBP that plays a vital role in various cellular processes, including transcription, cell cycle progression, angiogenesis and apoptosis (30-34). The prediction of the binding abundance between FUS and Grm1 was also determined using bioinformatics (http://pridb.gdcb.iastate.edu/RPISeq/). The binding scores of FUS and GRM1 are shown in Fig. 3E. The RIP assay revealed that Grm1 was highly bound to FUS in PASMCs (Fig. 3F).

The significance of the circRNA-protein interaction has recently been revealed, including via a $\mathrm{RBP}(35,36)$. The binding scores of FUS and circ-Grm1 are shown in Fig. 3G, and this this result was verified using a RIP assay. The RIP and pull-down assays demonstrated that circ-Grm1 showed a significant binding ability to FUS in PASMCs (Fig. 3H and I).

circ-Grml recruits FUS to inhibit Grm1 mRNA stability and expression. To further examine whether the circ-Grm1/FUS 

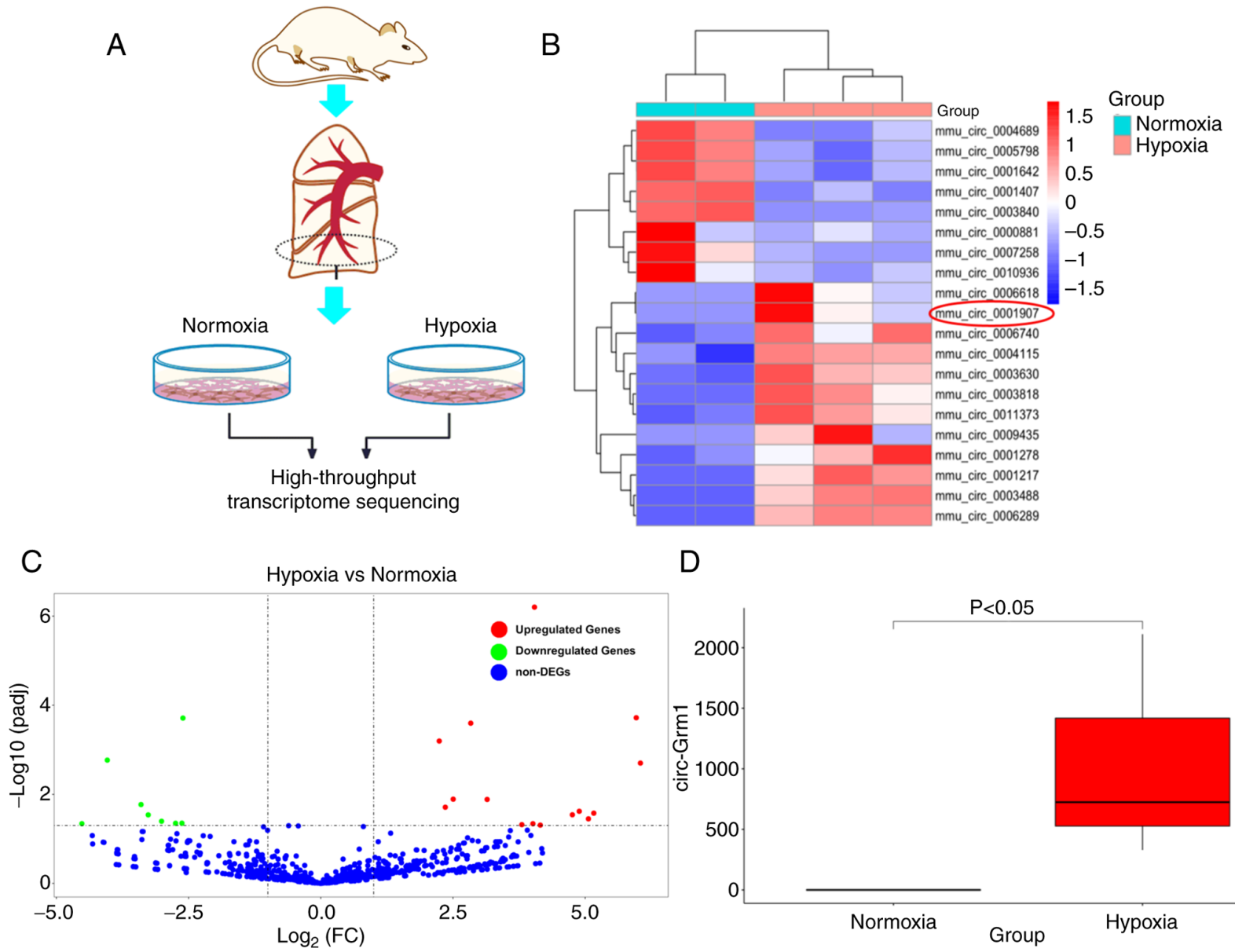

D

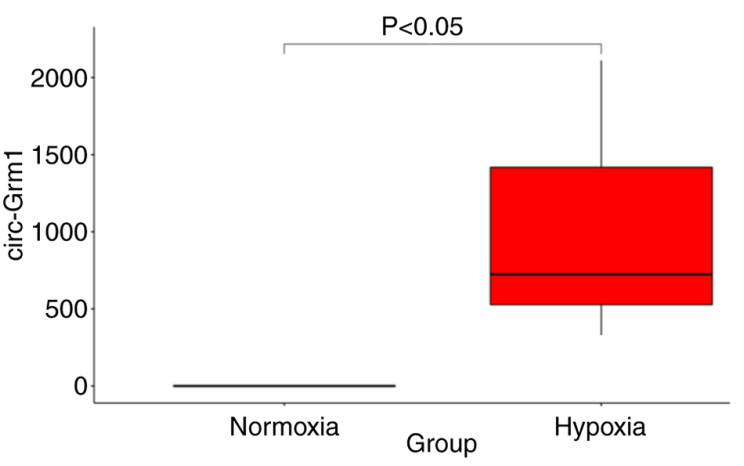

Figure 1. High-throughput transcriptome sequencing showed that circ-Grm1 is involved in the pathogenesis of pulmonary arterial hypertension in hypoxic PASMCs. (A) Primary culture of PASMCs from mice lung tissue. (B) Heat map and (C) Volcano map analysis of circular RNAs measured via high-throughput transcriptome sequencing analysis in hypoxic PASMCs. (D) High-throughput transcriptome sequencing analysis of circ-Grm1 expression in PASMCs of normoxia and hypoxia groups. PASMCs, pulmonary artery smooth muscle cells; circ, circular RNA; circ-Grm1, circular RNA glutamate metabotropic receptor 1; DEGs, differentially expressed genes.

complex could modulate the downstream genes of Grm1, the stability of the Grm1 mRNA was investigated in the presence of actinomycin D, a transcription inhibitor. The results of RNA stability assay indicated that the degradation rate of Grm1 mRNA was increased and decreased in PASMCs upon circ-Grm1 and FUS knockdown, respectively, compared with that of the control group at 0, 3, 6 and 9 h (Fig. 3J). These findings confirmed that circ-Grm1 could sponge FUS and suppress Grm1 mRNA stability. As shown in Fig. 3K, RT-qPCR was used to verify the expression level of Grm1 after FUS overexpression or knockdown and circ-Grm1 knockdown. The transfection efficiency of circ-Grm1 knockdown and FUS overexpression or knockdown was shown in Figs. 2A and S1 A and B, respectively. It was found that the knockdown effect of si-circ-2 group was higher. Therefore, si-circ-2 was selected for use in subsequent experiments experiment.

The results demonstrated that overexpression of FUS significantly increased the expression level of Grm1 in PASMCs (Fig. 3L), thereby suggesting that FUS expression was positively associated with Grm1 expression in PASMCs. Additionally, it was determined that the knockdown of circ-Grm1 significantly elevated Grm1 expression in PASMCs (Fig. 3M). Compared with the si-circ-Grm1 group, the co-transfection of si-circ-Grm1 and si-FUS significantly decreased the expression level of Grm1 (Fig. 3M). These findings indicated that the circ-Grm1/FUS complex could lead to the prohibition of mRNA stability and expression of Grm1.

Grml reverses the promoting role of circ-Grml in the hypoxia PASMCs. To investigate the effects of GRM1 in response to circ-Grm1, Grm1 was overexpressed in hypoxic PASMCs. The results of western blotting assays demonstrated the overexpression efficiency in the cells, which showed upregulation of GRM1 at the protein level (Fig. 4A). Moreover, the transfection efficiency of circ-Grm1 overexpression and Grm1 overexpression was examined via RT-qPCR (Fig. S1C and D). The CCK- 8 and EdU assays results demonstrated that the cell proliferative ability was inhibited after the co-transfection of oe-circ-Grm1 and pcDNA3.1-Grm1 compared with the co-transfection of oe-circ-Grm1 and pcDNA3.1-NC at 0, 24, 48, 72 and 96 h (Fig. 4B and C). Furthermore, the expression levels of proliferation-associated proteins (cyclin A, PCNA, CDK1 and Ki67) were detected via western blot analysis. As shown in Fig. 4D, the expression levels of these proteins were significantly upregulated after overexpression of circ-Grm1, whereas they were downregulated after the co-transfection of oe-circ-Grm1 and p-Grm1. Additionally, the wound healing 

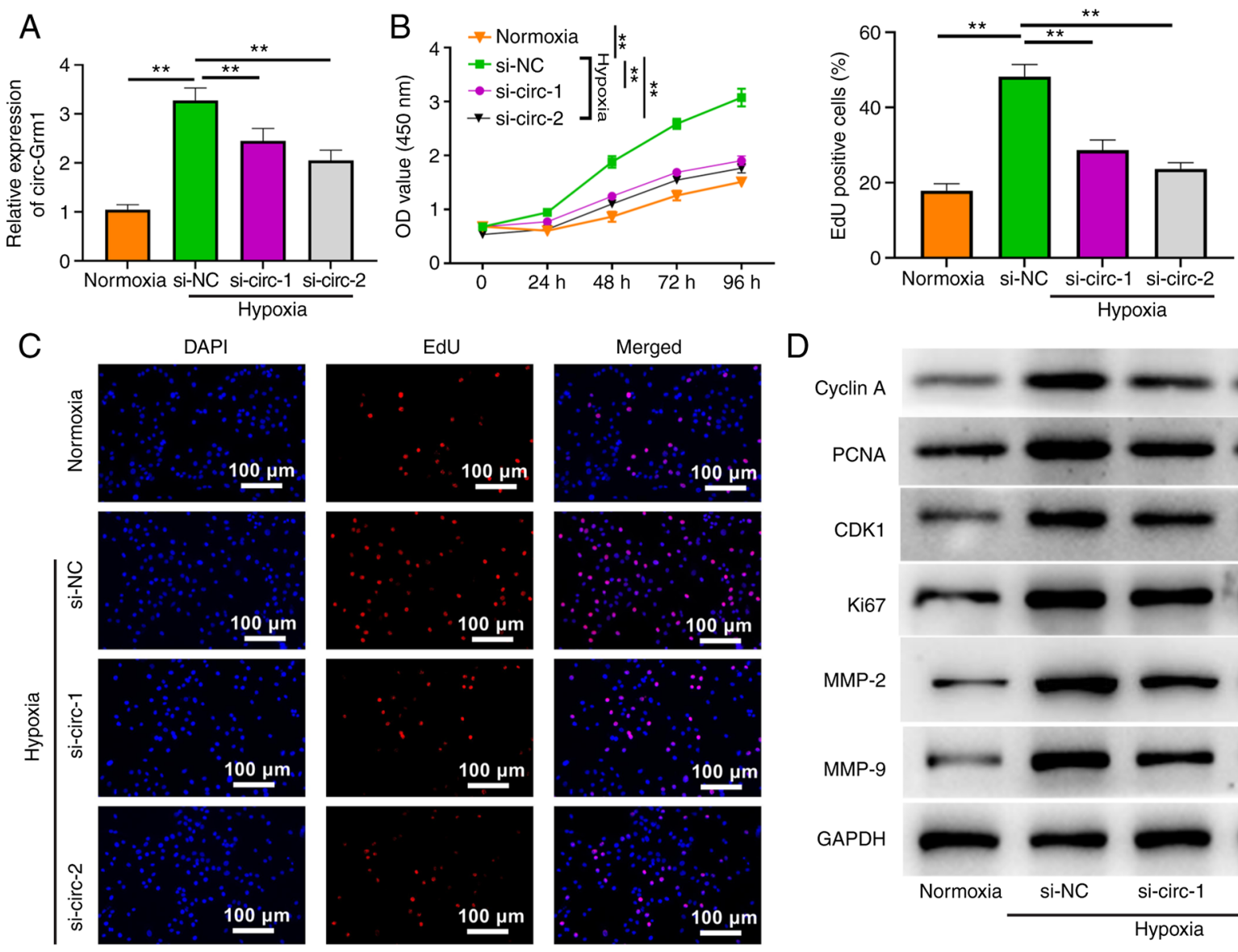

D
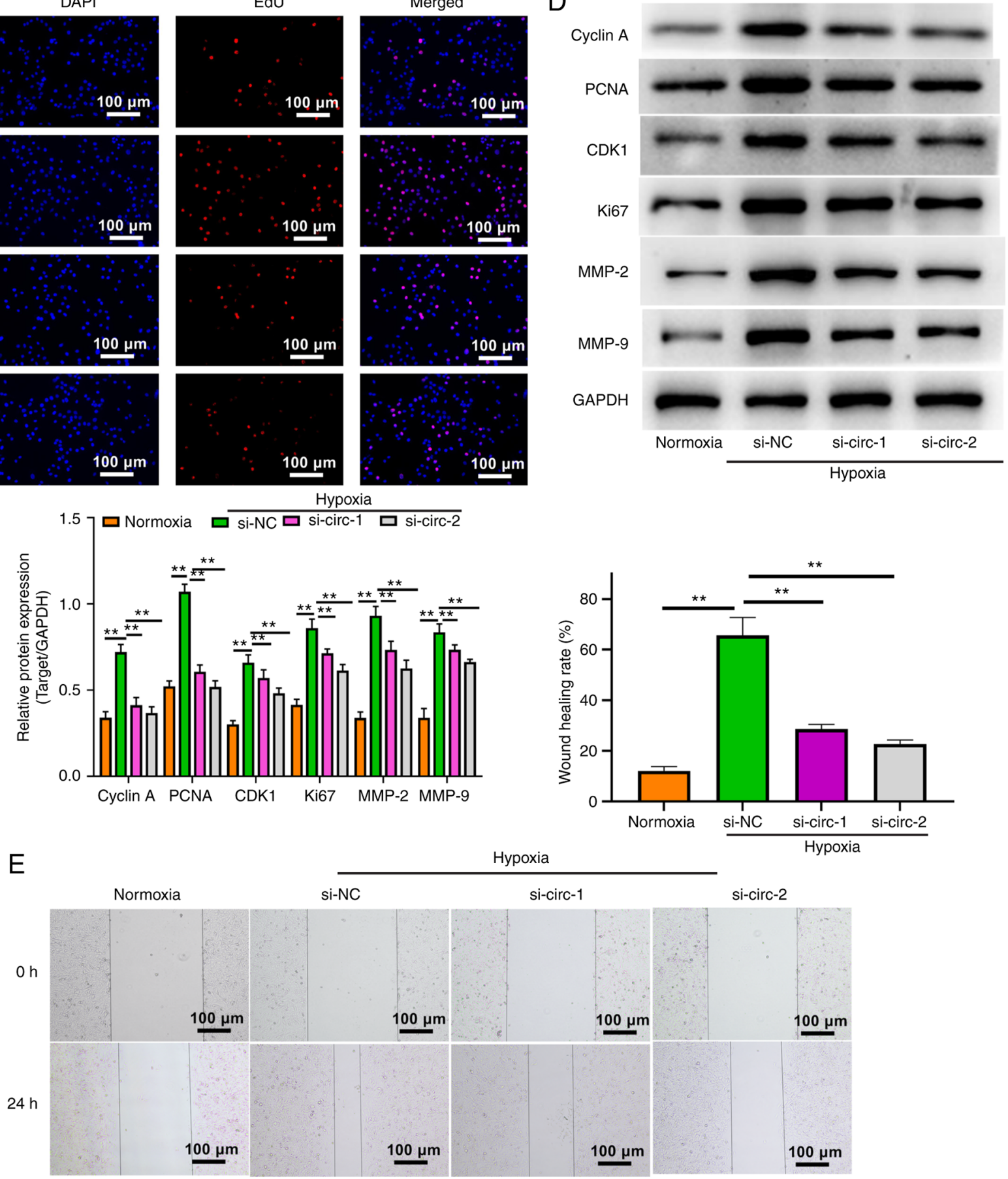

Figure 2. Silencing of circ-Grm1 suppresses the proliferation and migration of hypoxic PASMCs. (A) circ-Grm1 expression was detected via reverse transcription-quantitative PCR analysis in cells of normoxia, si-NC and si-circ-Grmlgroups. (B) Cell Counting Kit-8 assay and (C) EdU assays were performed to determine the proliferative ability of PASMCs in the normoxia, si-NC and si-circ-Grm1 groups. (D) Western blot analysis was performed to measure the expression levels of cyclin A, PCNA, CDK1, Ki67, MMP-2 and MMP-9 in cells from the normoxia, si-NC and si-circ-Grm1 groups. (E) Wound healing assay was performed to determine the migratory abilities of PASMCs. Scale bar, $100 \mu \mathrm{m}$. The experiments were independently conducted three times, and values are shown as the mean $\pm \mathrm{SD}$. " $\mathrm{P}<0.01$. EdU, 5-ethynyl-2-deoxyuridine; si, small interfering RNA; NC, negative control; PASMCs, pulmonary artery smooth muscle cells; circ, circular RNA; circ-Grm1, circular RNA glutamate metabotropic receptor 1; PCNA, proliferating cell nuclear antigen; OD, optical density. 
A

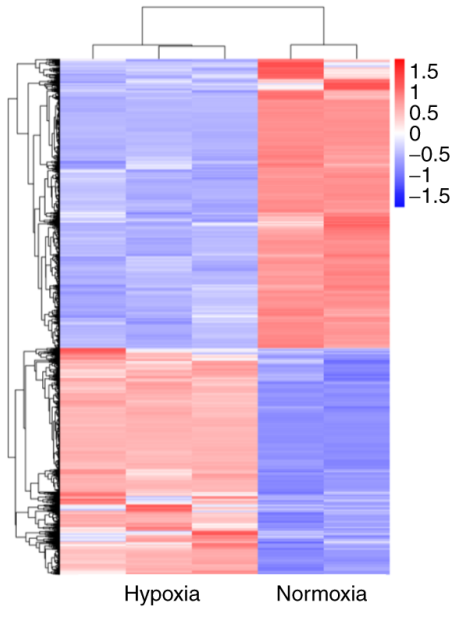

D

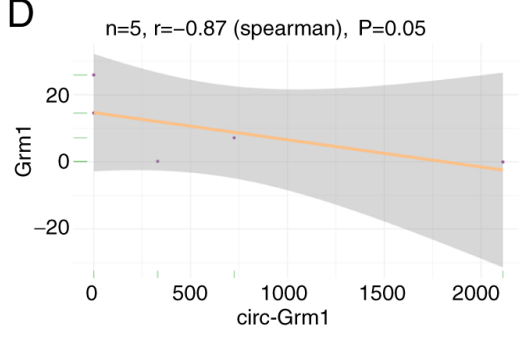

G

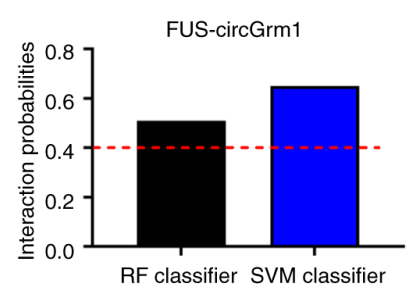

$J$

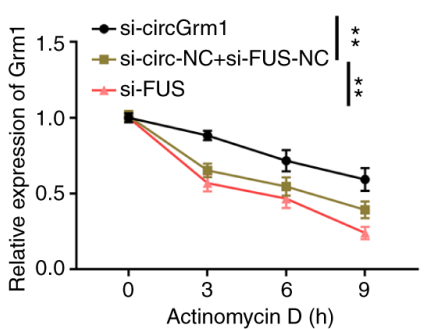

B

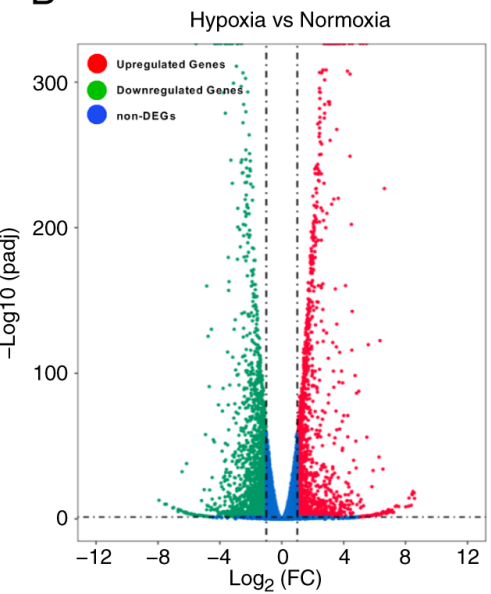

$E$
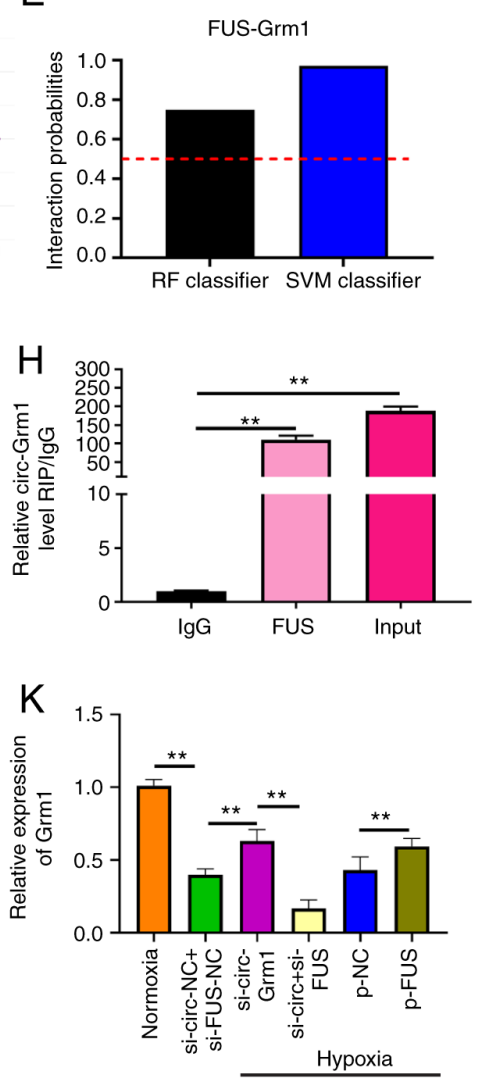

C

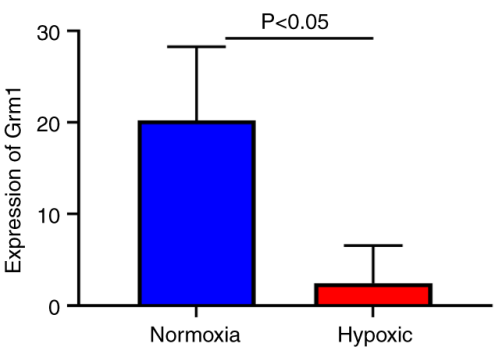

$\mathrm{F}$

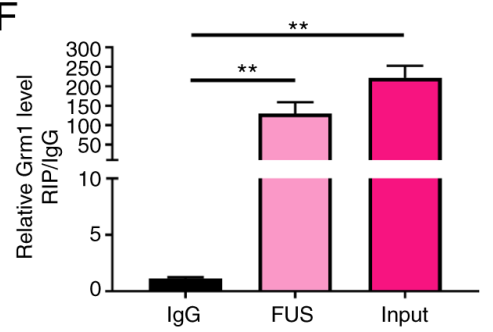

I

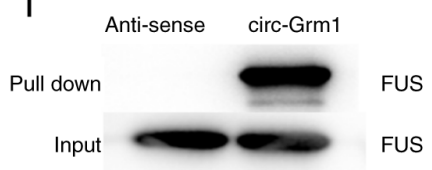

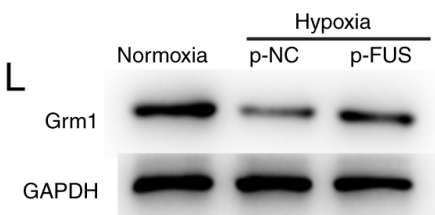

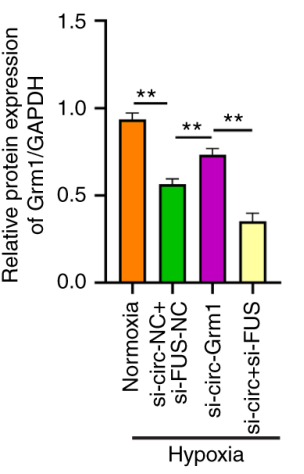

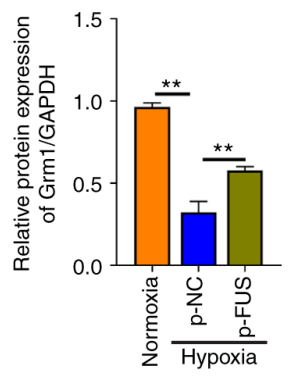

GAPDH

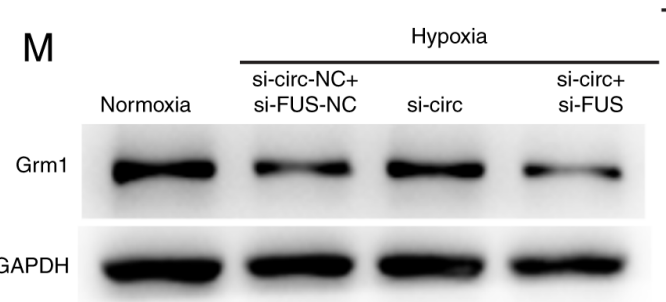

Figure 3. circ-Grm1 binds to FUS and suppresses Grm1 translation. (A) Volcano map and (B) heat map analysis measured via high-throughput transcriptome sequencing in normxia and hypoxic PASMCs. (C) Analysis of Grm1 expression in PASMCs via high-throughput transcriptome sequencing analysis. (D) Scatter plots were used to depict the correlations between circ-Grm1 and Grm1. (E) Interaction probabilities of Grm1 with FUS were predicted using bioinformatics analysis (predictions with $\mathrm{P}>0.5$ were considered 'positive'). (F) RIP assay showed that FUS precipitated with Grm1 in PASMCs. (G) Interaction probabilities of circ-Grm1 with FUS were predicted using bioinformatics analysis, which indicated that circ-Grm1 and FUS were likely to interact (predictions with P $>0.5$ were considered 'positive'). (H) RIP assays were conducted to detect the combination of circ-Grm1 and FUS, and then RT-qPCR was performed to detect the co-precipitated RNA. (I) Pull-down assay indicated that biotin-labelled circ-Grm1 interacted with FUS. (J) Actinomycin D was used to disturb RNA synthesis in PASMCs, and RT-qPCR was performed to detect the degradation rates of the RNA every $3 \mathrm{~h}$. (K) After transfection with si-circ-Grm1, si-FUS and p-FUS, RT-qPCR was used to detect Grm1 expression in PASMCs. After transfection with (L) p-FUS, (M) si-circ-Grm1 and si-FUS, western blotting was used to detect Grm1 expression in PASMCs. Values were presented as the mean \pm SD from three independent experiments. ${ }^{* *} \mathrm{P}<0.01$. RIP, RNA immunoprecipitation; RT-qPCR, reverse transcription-quantitative PCR; si, small interfering RNA; NC, negative control; PASMCs, pulmonary artery smooth muscle cells; circ, circular RNA; circ-Grm1, circular RNA glutamate metabotropic receptor 1; p-, pcDNA3.1; FC, fold change; RF, Random Forest; SVM, Support Vector Machine. 

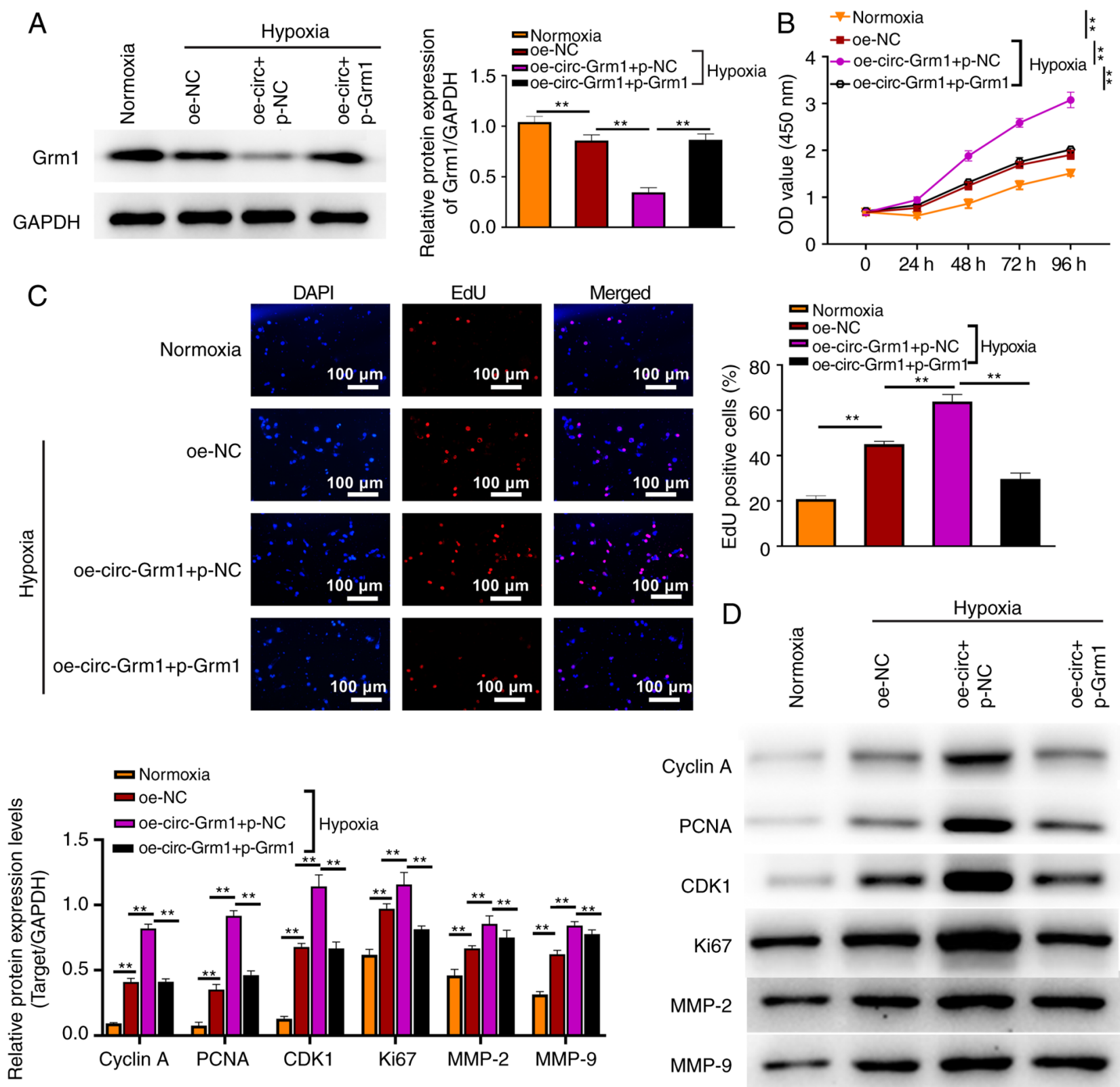

Cyclin A
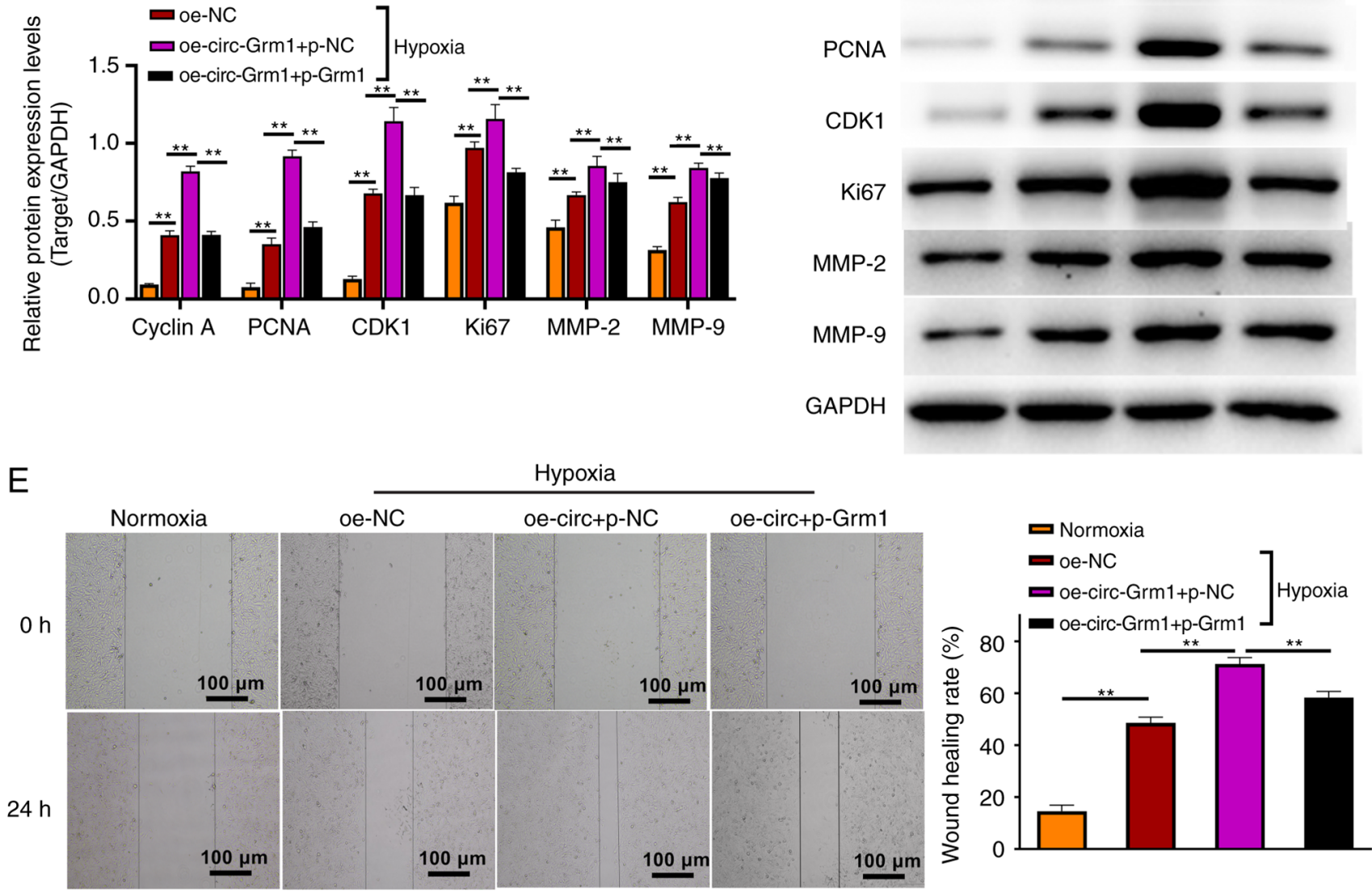

Figure 4. Grm1 reverses the promoting role of circ-Grm1 in the hypoxia PASMCs. (A) GRM1 expression in PASMCs from all groups was detected via western blotting. (B) Cell Counting Kit-8 and (C) EdU assays exhibited the proliferative ability of PASMCs in different groups. Scale bar, $100 \mu \mathrm{m}$. (D) Western blot analysis was performed to measure the expression levels of cyclin A, PCNA, CDK1, Ki67, MMP-2 and MMP-9 in normoxia and hypoxia PASMCs. (E) Wound healing assay was performed to detect the migratory ability of PASMCs. Values are shown as the mean $\pm \mathrm{SD}$ of three independent tests. ${ }^{* *} \mathrm{P}<0.01 . \mathrm{NC}$, negative control; PASMCs, pulmonary artery smooth muscle cells; circ, circular RNA; circ-Grm1, circular RNA glutamate metabotropic receptor 1; p-, pcDNA3.1; EdU, 5-ethynyl-2-deoxyuridine; OD, optical density; oe, overexpression; PCNA, proliferating cell nuclear antigen. 

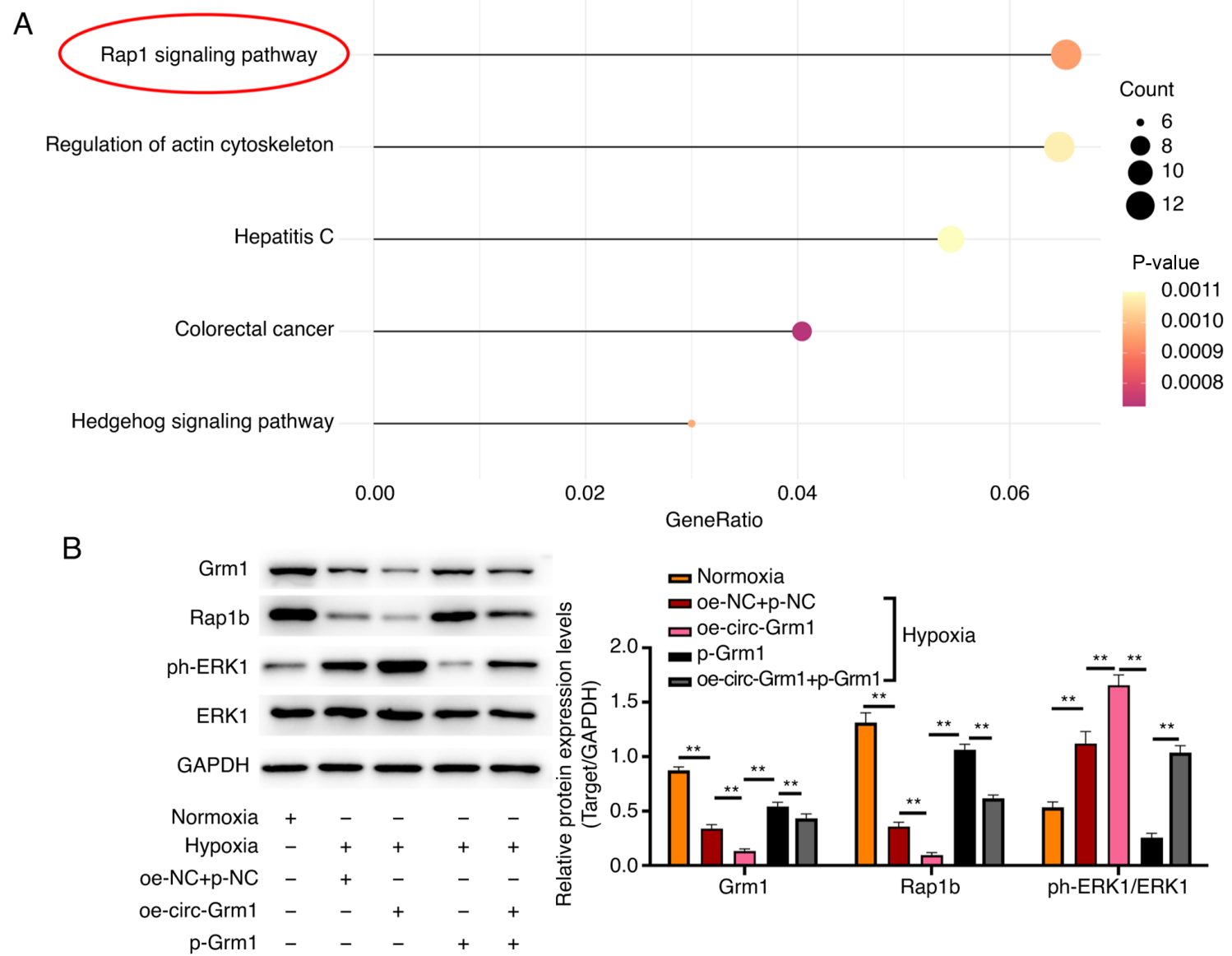

Figure 5. circ-Grm1 and Grm1 are associated with the function of PASMCs by regulating the Rap1 signalling pathway. (A) Kyoto Encyclopedia of Genes and Genomes (https://www.genome.jp/kegg/pathway.html) analysis was performed using the clusterProfiler R package. (B) Expression levels of Grm1, Raplb, p-ERK1 and ERK1 protein obtained in PASMCs from normoxia, hypoxia, oe-NC + p-NC, oe-circ-Grm1, p-Grm1 and oe-circ-Grm1 + p-Grm1 groups were detected via western blot analysis. Data are shown as the mean \pm SD based on three independent experiments. ${ }^{* *} \mathrm{P}<0.01$. NC, negative control; PASMCs, pulmonary artery smooth muscle cells; circ, circular RNA; circ-Grm1, circular RNA glutamate metabotropic receptor 1; p-, pcDNA3.1; ph-, phosphorylated.

assay results suggested that overexpression of circ-Grm1 significantly increased the migration of PASMCs. However, after the co-transfection of oe-circ-Grm1 and p-Grm1, the migratory ability of PASMCs was impaired (Fig. 4E). MMPs modulate extracellular matrix composition and integrity, and MMP-2 and 9 play key roles in cleaving the extracellular matrix components that contribute to cell migration and vascular remodelling $(37,38)$. Thus, the migration results were also verified by detecting the expression levels of migration-associated proteins, MMP-2 and MMP-9. These findings suggested that Grm1 could inhibit the function of circ-Grm1 with the promotion of the proliferative and migratory abilities in hypoxic PASMCs.

circ-Grm1 and Grm1 are involved in function of PASMCs by regulating the Rapl signalling pathway. The effects of circ-Grm1 and Grm1 on the signalling pathways were determined using KEGG analysis and western blotting. The 'Rap1 signalling pathway' was significantly associated with the circ-Grm1 and Grm1 in HPH (Fig. 5A). Additionally, the western blotting results indicated that the protein expression levels of Grm1 and Raplb in the hypoxia groups were lower compared with those of the normoxia group, whereas these were increased in cells overexpressing Grm1 compared with oe-circ-Grm1 group (Fig. 5B). Conversely, the expression level of ph-ERK1 in the hypoxia groups was higher compared with the control group, whereas it was lower in cells with overexpressing Grm1 compared with oe-circ-Grm1 group (Fig. 5B). In addition, the co-transfection of oe-circ-Grm1 and p-Grm1 reversed the effects of Grm1 overexpression on the expression levels of Grm1, Rap1b and ph-ERK1. Therefore, it was suggested that circ-Grm1 could inhibit the biological functionalities of the Rap1 signalling pathway in PASMCs in HPH and promote the phosphorylation of ERK1.

\section{Discussion}

A previous study revealed that hypoxia-induced pulmonary hypertension was mainly caused by hypoxic pulmonary vasoconstriction, pulmonary vascular remodelling and polycythaemia (39). Pulmonary vascular remodelling is a key feature of hypoxia-induced pulmonary hypertension associated with the dysfunction of endothelial cells, smooth muscle cells and fibroblasts (40). Previous studies have shown that circRNAs are involved in PASMC proliferation, migration and apoptosis, leading to pulmonary vascular remodelling $(4,41)$. In the present study, to the best of our knowledge, it was demonstrated for the first time that circ-Grm1 was involved in HPH and the mechanisms via which circRNA regulated PASMC proliferation and migration were shown in Fig. 6. 


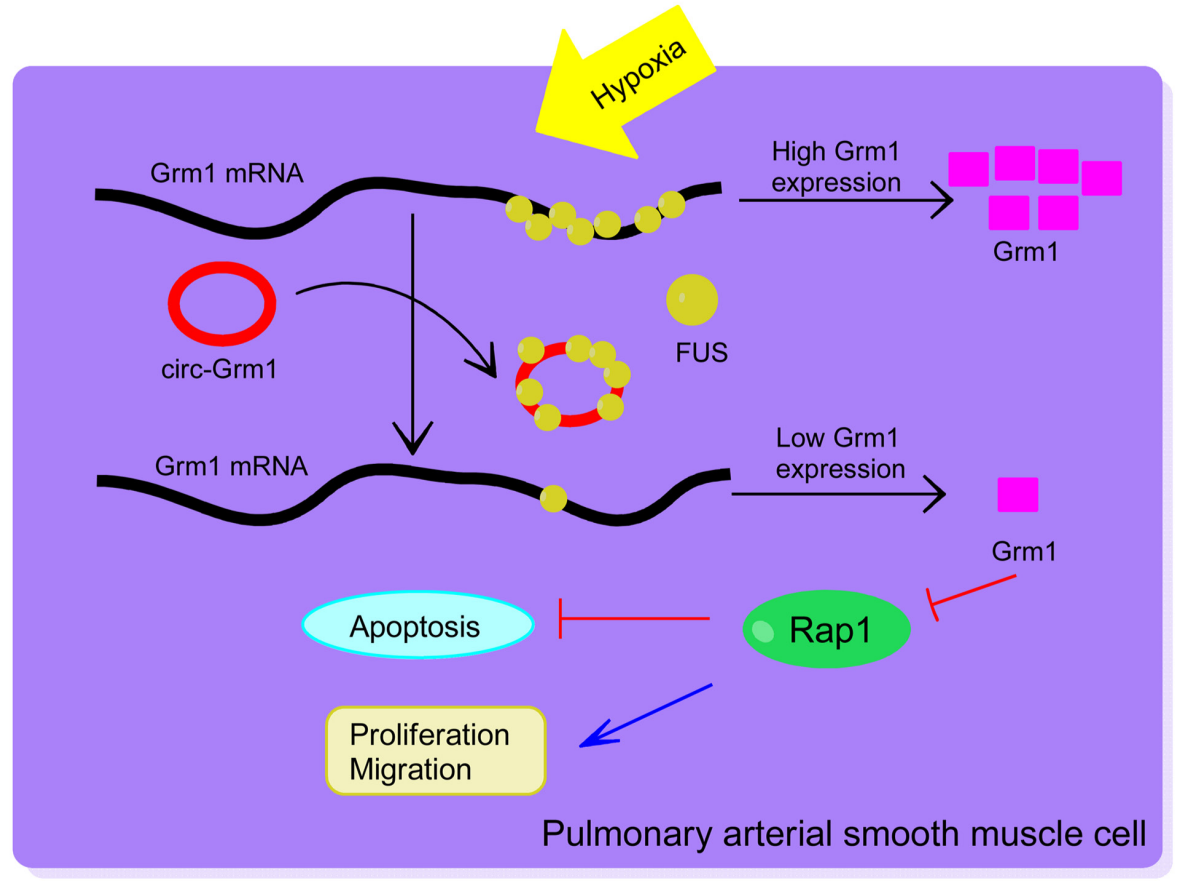

Figure 6. A circ-Grm1/Grm1/Rap1 signalling axis regulates the proliferation and migration of pulmonary artery smooth muscle cells in hypoxia-induced pulmonary arterial hypertension. circ, circular RNA; circ-Grm1, circular RNA glutamate metabotropic receptor 1; FUS, FUS RNA binding protein.

As a non-coding RNA, circRNA was recently discovered. Previous studies have reported that circRNAs are associated with vascular dysfunction and multiple processes, such as vascular development, growth and remodelling (42-48). The present study performed a high-throughput transcriptome sequencing analysis of the PASMCs to investigate the differently expressed circRNAs and finally identified the upregulated circ-Grm1. circ-Grm1 was first found to be upregulated in hypoxic PASMC models, as determined by high-throughput transcriptome sequencing. The functional cellular experiments revealed that the knockdown of circ-Grm1 could effectively inhibit the proliferation and migration of PASMCs in vitro. Therefore, these results indicated that circ-Grm1 participates in the regulation of the biological function of PASMCs.

circRNA plays a vital role in regulating downstream molecules, such as Grm1. As a G-protein-coupled receptor, Grm1 is normally localized to the central and peripheral nervous systems. Grm1 is correlated with cell proliferation, migration and invasion in prostate cancer (49). It has been shown that Grm1 activation is coupled with ERK1/2 (50). Moreover, activation of ERK1/2 via phosphorylation on tyrosine and threonine residues plays a pivotal role in intracellular signalling and can mediate cellular processes, such as cell proliferation, invasion, metastasis, survival angiogenesis and apoptosis $(51,52)$.

As aforementioned, the high-throughput transcriptome sequencing analysis results identified that circ-Grm1 was upregulated in hypoxic PASMC models, but the expression of its cognate mRNA (Grm1) was significantly decreased. To clarify this phenomenon, we hypothesized that FUS could mediate the expression of circ-Grm1 and Grm1. Therefore, bioinformatics analysis was used to predict whether circ-Grm1 and Grm1 may bind to FUS. The RIP and pull-down assays revealed that FUS could interact with both circ-Grm1 and Grm1. Based on the observed FUS binding to circ-Grm1 and Grm1 mRNA, Grm1 expression following circ-Grm1 knockdown or FUS overexpression was increased, but decreased following FUS knockdown. Cui and Placzek (53) and Zhao et al (54) reported that mRNA translation and mRNA stability were major factors contributing to protein expression levels. Thus, to test this, si-NC, circ-Grm1 and si-FUS transfected cells were treated with actinomycin $\mathrm{D}$ to block transcription, and incremental RNA samples were harvested to assess Grm1 mRNA half-life. The RNA stability assay demonstrated that linear regression decay curves of Grm1 mRNA showed an increase and decrease in half-life for si-circ-Grm1 and si-FUS transfected PASMCs under hypoxia, respectively. These results suggested that circ-Grm1 could sponge FUS and suppresses Grm1 mRNA stability and Grm1 protein expression.

The present study found that Grm1 reversed the boosting function of circ-Grm1 in the progression of HPH. Previous reports have shown that circ- 0000790 monitors FOXC1 by binding to miR-374c, and affects the biological functionalities of PASMCs in mice in the HPH model, whereas miR-374c reversed the enhanced functionalities of mmu_circ_0000790 of silencing-RNA groups with the progression of HPH (4). Therefore, these results indicated that circ-Grm1 participates in the regulation of PASMCs' biological function.

circRNAs act as molecular connectors for proteins, which were combined with corresponding pathways. In the present study, circ-Grm1 was upregulated in hypoxic PASMCs and competed with binding of FUS (an RBP), which could inhibit the expression of downstream transcripts of Grm1. Then, the Rap1 signalling pathway was inhibited and accompanied by activation of the ERK signalling pathway. Rap1 is associated with the mass of cellular signal transduction pathways, which have been associated with proliferative and migratory cell phenotypes (55), and the signalling pathway of ERK acts as a 
significant modulator in proliferation, differentiation, migration, senescence and apoptosis in cells $(56,57)$. Nikam et al (58) reported that reduced p-ERK expression could have been responsible for the slower growth rate of HMVECs following the suppression of Rapla or $-1 \mathrm{~b}$ expression. Studies have also shown that Rap1 activated GAP-GTP by immediately restraining the reactivities of the phosphorylation of ERK to promote proliferation and migration in VSMCs (59), and this was also demonstrated in the present study. The current results demonstrated that the circ-Grm1/Grm1/Rap1 signalling axis regulated PASMC proliferation and migration in hypoxia-induced $\mathrm{PAH}$, thereby providing a new potential target for the treatment and diagnosis of this disease.

In conclusion, the present study identified that circ-Grm1 was involved in vascular remodelling in PAH by promoting the proliferation and migration of PASMCs via suppression of GRM1 expression by FUS. Furthermore, it was found that the Rap1 signalling pathway was also involved in this process. Taken together, the current results suggest that circ-Grm1 may be used as a novel biomarker in the diagnosis and treatment of PAH.

\section{Acknowledgements}

Not applicable.

\section{Funding}

This research was supported by Shandong Key Research and Development Plan (grant nos. 2019GSF108186 and 2014GSF118066), Shandong, China.

\section{Availability of data and materials}

The datasets used and/or analyzed during the current study are available from the corresponding author on reasonable request. The RNA-seq datasets in this manuscript have been deposited in the National Center for Biotechnology Information Sequence Read Archive (http://www.ncbi.nlm. nih.gov/sra) under BioProject no. PRJNA753221 (accession nos. SRR15440746 and SRR15403718).

\section{Authors' contributions}

Conception and design: SS. Performed research: QK, ZC and MW. Data analysis and interpretation: SS, HZ and CZ. Manuscript writing: SS. The authenticity of the raw data has been assessed by SS and CZ. All authors read and approved the final manuscript.

\section{Ethics approval and consent to participate}

This experiment was conducted with approval of the Animal Ethics Committee of Qilu Hospital of Shandong University (approval no. KYLL-2020-002). All animal experiments in this study were in strict accordance with the protocols stated in the Guide for the Care and Use of Laboratory Animals published by the US National Institutes of Health. Appropriate measures were taken to minimize the number and suffering of animals.

\section{Patient consent for publication}

Not applicable.

\section{Competing interests}

The authors declared no potential conflicts of interest with respect to the research, authorship, and/or publication of this article.

\section{References}

1. Lau EMT, Giannoulatou E, Celermajer DS and Humbert M: Epidemiology and treatment of pulmonary arterial hypertension. Nat Rev Cardiol 14: 603-614, 2017.

2. Thenappan T, Ryan JJ and Archer SL: Evolving epidemiology of pulmonary arterial hypertension. Am J Respir Crit Care Med 186: 707-709, 2012.

3. Zolty R: Pulmonary arterial hypertension specific therapy: The old and the new. Pharmacol Ther 214: 107576, 2020.

4. Xu L, Ma Y, Zhang H, Lu QJ, Yang L, Jiang GN and Liao WL: HMGA2 regulates circular RNA ASPH to promote tumor growth in lung adenocarcinoma. Cell Death Dis 11: 593, 2020.

5. Mulvaney EP, Reid HM, Bialesova L, Mendes-Ferreira P, Adão R, Brás-Silva C and Kinsella BT: Efficacy of the thromboxane receptor antagonist NTP42 alone, or in combination with sildenafil, in the sugen/hypoxia-induced model of pulmonary arterial hypertension. Eur J Pharmacol 889: 173658, 2020.

6. Sitbon O, Gomberg-Maitland M, Granton J, Lewis MI, Mathai SC, Rainisio M, Stockbridge NL, Wilkins MR, Zamanian RT and Rubin LJ: Clinical trial design and new therapies for pulmonary arterial hypertension. Eur Respir J 53: 1801908, 2019.

7. McLaughlin VV, Hoeper MM, Channick RN, Chin KM, Delcroix M, Gaine S, Ghofrani HA, Jansa P, Lang IM, Mehta S, et al: Pulmonary arterial hypertension-related morbidity is prognostic for mortality. J Am Coll Cardiol 71: 752-763, 2018.

8. Galiè N, Humbert M, Vachiery JL, Gibbs S, Lang I, Torbicki A, Simonneau G, Peacock A, Noordegraaf AV, Beghetti M, et al: 2015 ESC/ERS guidelines for the diagnosis and treatment of pulmonary hypertension. Rev Esp Cardiol (Engl Ed) 69: 177, 2016.

9. Chaabane M, Andreeva K, Hwang JY, Kook TL, Park JW and Cooper NGF: seekCRIT: Detecting and characterizing differentially expressed circular RNAs using high-throughput sequencing data. PLoS Comput Biol 16: e1008338, 2020.

10. Du H, He Z, Feng F, Chen D, Zhang L, Bai J, Wu H, Han E and Zhang J: Hsa_circ_0038646 promotes cell proliferation and migration in colorectal cancer via miR-331-3p/GRIK3. Oncol Lett 20: 266-274, 2020.

11. Song R, Li Y, Hao W, Yang L, Chen B, Zhao Y, Sun B and Xu F: Circular RNA MTO1 inhibits gastric cancer progression by elevating PAWR via sponging miR-199a-3p. Cell Cycle 19: 3127-3139, 2020

12. Altesha MA, Ni T, Khan A, Liu K and Zheng X: Circular RNA in cardiovascular disease. J Cell Physiol 234: 5588-5600, 2019.

13. Boon RA, Jaé N, Holdt L and Dimmeler S: Long noncoding RNAs: From clinical genetics to therapeutic targets? J Am Coll Cardiol 67: 1214-1226, 2016.

14. Miao R, Wang Y, Wan J, Leng D, Gong J, Li J, Liang Y, Zhai Z and Yang Y: Microarray expression profile of circular RNAs in chronic thromboembolic pulmonary hypertension. Medicine (Baltimore) 96: e7354, 2017.

15. Wang Y, Tan X, Wu Y, Cao S, Lou Y, Zhang L and Hu F: Hsa circ_0002062 promotes the proliferation of pulmonary artery smooth muscle cells by regulating the Hsa-miR-942-5p/CDK6 signaling pathway. Front Genet 12: 673229, 2021.

16. Yang L, Liang H, Meng X, Shen L, Guan Z, Hei B, Yu H, Qi S and Wen X: mmu_circ_0000790 is involved in pulmonary vascular remodeling in mice with HPH via microRNA-374c-mediated FOXC1. Mol Ther Nucleic Acids 20: 292-307, 2020

17. Abdelmohsen K, Panda AC, Munk R, Grammatikakis I, Dudekula DB, De S, Kim J, Noh JH, Kim KM, Martindale JL and Gorospe M: Identification of HuR target circular RNAs uncovers suppression of PABPN1 translation by CircPABPN1. RNA Biol 14: 361-369, 2017. 
18. Du WW, Fang L, Yang W, Wu N, Awan FM, Yang Z and Yang BB: Induction of tumor apoptosis through a circular RNA enhancing Foxo3 activity. Cell Death Differ 24: 357-370, 2017.

19. Wang J, Song YX, Ma B, Wang JJ, Sun JX, Chen XW, Zhao JH, Yang YC and Wang ZN: Regulatory roles of non-coding RNAs in colorectal cancer. Int J Mol Sci 16: 19886-19919, 2015.

20. Fan YN, Li C, Huang L, Chen L, Tang Z, Han G and Liu Y: Characterization of group I metabotropic glutamate receptors in rat and human adrenal glands. Front Physiol 11: 401, 2020.

21. Khan AJ, LaCava S, Mehta M, Schiff D, Thandoni A, Jhawar S, Danish S, Haffty BG and Chen S: The glutamate release inhibitor riluzole increases DNA damage and enhances cytotoxicity in human glioma cells, in vitro and in vivo. Oncotarget 10 : 2824-2834, 2019.

22. Namkoong J, Martino JJ and Chen S: From existing therapies to novel targets: A current view on melanoma. Front Biosci 11: 2081-2092, 2006.

23. Yip D, Le MN, Chan JL, Lee JH, Mehnert JA, Yudd A, Kempf J, Shih WJ, Chen S and Goydos JS: A phase 0 trial of riluzole in patients with resectable stage III and IV melanoma. Clin Cancer Res 15: 3896-3902, 2009.

24. Wang R, Xu YJ, Liu XS, Zeng DX and Xiang M: Knockdown of connective tissue growth factor by plasmid-based short hairpin RNA prevented pulmonary vascular remodeling in cigarette smoke-exposed rats. Arch Biochem Biophys 508: 93-100, 2011.

25. Wang R, Xu YJ, Liu XS, Zeng DX and Xiang M: CCN2 promotes cigarette smoke-induced proliferation of rat pulmonary artery smooth muscle cells through upregulating cyclin D1 expression. J Cell Biochem 113: 349-359, 2012.

26. Livak KJ and Schmittgen TD: Analysis of relative gene expression data using real-time quantitative PCR and the 2(-Delta Delta C(T)) method. Methods 25: 402-408, 2001

27. Kong W, Wei J, Abidi P, Lin M, Inaba S, Li C, Wang Y, Wang Z, $\mathrm{Si} \mathrm{S}$, Pan $\mathrm{H}$, et al: Berberine is a novel cholesterol-lowering drug working through a unique mechanism distinct from statins. Nat Med 10: 1344-1351, 2004.

28. Muller C, Goubin F, Ferrandis E, Cornil-Scharwtz I, Bailly JD, Bordier C, Bénard J, Sikic BI and Laurent G: Evidence for transcriptional control of human mdrl gene expression by verapamil in multidrug-resistant leukemic cells. Mol Pharmacol 47: 51-56, 1995

29. Yu G, Wang LG, Han Y and He QY: clusterProfiler: An R package for comparing biological themes among gene clusters OMICS 16: 284-287, 2012

30. Deng WG, Kawashima H, Wu G, Jayachandran G, Xu K, Minna JD, Roth JA and Ji L: Synergistic tumor suppression by coexpression of FUS1 and p53 is associated with down-regulation of murine double minute- 2 and activation of the apoptotic protease-activating factor 1-dependent apoptotic pathway in human non-small cell lung cancer cells. Cancer Res 67: 709-717, 2007.

31. Hesson LB, Cooper WN and Latif F: Evaluation of the $3 \mathrm{p} 21.3$ tumour-suppressor gene cluster. Oncogene 26: 7283-7301, 2007.

32. Ji L and Roth JA: Tumor suppressor FUS1 signaling pathway. J Thorac Oncol 3: 327-330, 2008.

33. Lin J, Sun T, Ji L, Deng W, Roth J, Minna J and Arlinghaus R: Oncogenic activation of c-Abl in non-small cell lung cancer cells lacking FUS1 expression: Inhibition of c-Abl by the tumor suppressor gene product Fus1. Oncogene 26: 6989-6996, 2007.

34. Zou Z, Ma T, He X, Zhou J, Ma H, Xie M, Liu Y, Lu D, Di S and Zhang Z: Long intergenic non-coding RNA 00324 promotes gastric cancer cell proliferation via binding with $\mathrm{HuR}$ and stabilizing FAM83B expression article. Cell Death Dis 9: 717, 2018.

35. Du WW, Zhang C, Yang W, Yong T, Awan FM and Yang BB: Identifying and characterizing circRNA-protein interaction. Theranostics 7: 4183-4191, 2017.

36. Hentze MW and Preiss T: Circular RNAs: Splicing's enigma variations. EMBO J 32: 923-925, 2013.

37. Li YX, Run L, Shi Tand Zhang YJ:CTRP9 regulates hypoxia-mediated human pulmonary artery smooth muscle cell proliferation, apoptosis and migration via TGF- $\beta 1 /$ ERK1/2 signaling pathway. Biochem Biophys Res Commun 490: 1319-1325, 2017.

38. You B, Liu Y, Chen J, Huang X, Peng H, Liu Z, Tang Y, Zhang K Xu Q, Li X, et al: Vascular peroxidase 1 mediates hypoxia-induced pulmonary artery smooth muscle cell proliferation, apoptosis resistance and migration. Cardiovasc Res 114: 188-199, 2018.

39. Naeije R and Dedobbeleer C: Pulmonary hypertension and the right ventricle in hypoxia. Exp Physiol 98: 1247-1256, 2013.

40. Ghofrani HA, Voswinckel R, Reichenberger F, Weissmann N, Schermuly RT, Seeger W and Grimminger F: Hypoxia- and non-hypoxia-related pulmonary hypertension-established and new therapies. Cardiovasc Res 72: 30-40, 2006.
41. Zhou S, Jiang H, Li M, Wu P, Sun L, Liu Y, Zhu K, Zhang B, Sun G, Cao C and Wang R: Circular RNA hsa_circ_0016070 is associated with pulmonary arterial hypertension by promoting PASMC proliferation. Mol Ther Nucleic Acids 18: 275-284, 2019

42. Beltrán-García J, Osca-Verdegal R, Nácher-Sendra E, Cardona-Monzonís A,Sanchis-GomarF, Carbonell N, PallardóFV, Lavie CJ and García-Giménez JL: Role of non-coding RNAs as biomarkers of deleterious cardiovascular effects in sepsis. Prog Cardiovasc Dis: Jul 13, 2021 (Epub ahead of print).

43. Li R, Jiang Q and Zheng Y: Circ_0002984 induces proliferation, migration and inflammation response of VSMCs induced by ox-LDL through miR-326-3p/VAMP3 axis in atherosclerosis. J Cell Mol Med 25: 8028-8038, 2021.

44. Wang F and Zhang M: Circ_001209 aggravates diabetic retinal vascular dysfunction through regulating miR-15b-5p/COL12A1. J Transl Med 19: 294, 2021.

45. Zhu QQ, Pu XB, Chen TC, Qiu CY, Wu ZH, Tian L, He YY, Wang XH, Shang T, Wang X, et al: Hsa circ 0008360 sponges miR-186-5p to target CCND2 to modulate high glucose-induced vascular endothelial dysfunction. Cell Cycle 20: 1389-1401,2021

46. Guo HM and Liu ZP: Up-regulation of circRNA_0068481 promotes right ventricular hypertrophy in PAH patients via regulating miR-646/miR-570/miR-885. J Cell Mol Med 25: 3735-3743, 2021.

47. Hong L, Ma X, Liu J, Luo Y, Lin J, Shen Y and Zhang L: Circular RNA-HIPK3 regulates human pulmonary artery endothelial cells function and vessel growth by regulating microRNA-328-3p/STAT3 axis. Pulm Circ 11: 20458940211000234, 2021.

48. Yang T, Long T, Du T, Chen Y, Dong Y and Huang ZP: Circle the cardiac remodeling with circRNAs. Front Cardiovasc Med 8 702586, 2021.

49. Ali S, Shourideh M and Koochekpour S: Identification of novel GRM1 mutations and single nucleotide polymorphisms in prostate cancer cell lines and tissues. PLoS One 9: e103204, 2014.

50. Thandi S, Blank JL and Challiss RAJ: Group-I metabotropic glutamate receptors, mGlu1a and mGlu5a, couple to extracellular signal-regulated kinase (ERK) activation via distinct, but overlapping, signalling pathways. J Neurochem 83: 1139-1153, 2002.

51. Inamdar GS, Madhunapantula SRV and Robertson GP: Targeting the MAPK pathway in melanoma: Why some approaches succeed and other fail. Biochem Pharmacol 80: 624-637, 2010.

52. Pearson G, Robinson F, Beers Gibson T, Xu BE, Karandikar M, Berman K and Cobb MH: Mitogen-activated protein (MAP) kinase pathways: Regulation and physiological functions. Endocr Rev 22: $153-183,2001$

53. Cui J and Placzek WJ: PTBP1 modulation of MCL1 expression regulates cellular apoptosis induced by antitubulin chemotherapeutics. Cell Death Differ 23: 1681-1690, 2016.

54. Zhao Y, Liu Y, Lin L, Huang Q, He W, Zhang S, Dong S, Wen Z, Rao J, Liao W and Shi M: The lncRNA MACC1-AS1 promotes gastric cancer cell metabolic plasticity via AMPK/Lin28 mediated mRNA stability of MACC1. Mol Cancer 17: 69, 2018.

55. Zhu B, Cao A, Li J, Young J, Wong J, Ashraf S, Bierzynska A, Menon MC, Hou S, Sawyers C, et al: Disruption of MAGI2RapGEF2-Rap1 signaling contributes to podocyte dysfunction in congenital nephrotic syndrome caused by mutations in MAGI2. Kidney Int 96: 642-655, 2019.

56. Liang D, Xiang L, Yang M, Zhang X, Guo B, Chen Y, Yang L and Cao J: ZnT7 can protect MC3T3-E1 cells from oxidative stress-induced apoptosis via PI3K/Akt and MAPK/ERK signaling pathways. Cell Signal 25: 1126-1135, 2013.

57. Ma H, Han F, Yan X, Qi G, Li Y, Li R, Yan S, Yuan C, Song K and Kong B: PBK promotes aggressive phenotypes of cervical cancer through ERK/c-Myc signaling pathway. J Cell Physiol 236: 2767-2781, 2020

58. Nikam VS, Wecker G, Schermuly R, Rapp U, Szelepusa K, Seeger W and Voswinckel R: Treprostinil inhibits the adhesion and differentiation of fibrocytes via the cyclic adenosine monophosphate-dependent and Ras-proximate protein-dependent inactivation of extracellular regulated kinase. Am J Respir Cell Mol Biol 45: 692-703, 2011.

59. Li Q, Teng Y, Wang J, Yu M, Li Y and Zheng H: Rap1 promotes proliferation and migration of vascular smooth muscle cell via the ERK pathway. Pathol Res Pract 214: 1045-1050, 2018.

This work is licensed under a Creative Commons Attribution-NonCommercial-NoDerivatives 4.0 International (CC BY-NC-ND 4.0) License. 